\title{
Free fatty acids promote degranulation of azurophil granules in neutrophils by inducing production of NADPH oxidase-derived reactive oxygen species in cows with subclinical ketosis
}

\author{
Yuxiang Song, ${ }^{1 *}$ Shang Jiang, ${ }^{1 *}$ Congyi Li, ${ }^{1}$ Juan J. Loor, ${ }^{2}$ Qianming Jiang, ${ }^{2}$ Yuchen Yang, ${ }^{1}$ \\ Xiancheng Feng, ${ }^{1}$ Siyuan Liu, ${ }^{1}$ Jiyuan He, ${ }^{1}$ Kexin Wang, ${ }^{1}$ Yunfei Li, ${ }^{1}$ Cai Zhang, ${ }^{3}$ Xiliang Du, ${ }^{1}$ Zhe Wang, ${ }^{1}$ \\ Xinwei Li, ${ }^{1}$ and Guowen Liu ${ }^{1} \dagger$ \\ ${ }^{1}$ Key Laboratory of Zoonosis, Ministry of Education, College of Veterinary Medicine, Jilin University, Changchun, Jilin Province, 130062 China \\ ${ }^{2}$ Mammalian NutriPhysioGenomics, Department of Animal Sciences, Division of Nutritional Sciences, University of Illinois, Urbana 61801 \\ ${ }^{3}$ College of Animal Science and Technology, Henan University of Science and Technology, Luoyang, 471003 China
}

\begin{abstract}
Subclinical ketosis (SCK) in dairy cows, a common metabolic disorder during the peripartal period, is accompanied by systemic inflammation. Excessive release of azurophil granule (AG) contents during degranulation of polymorphonuclear neutrophils (PMN) could contribute to systemic inflammation in SCK cows. Although the increase in blood free fatty acids (FFA) in SCK cows may promote AG degranulation from PMN, the underlying mechanisms are unclear. Thirty multiparous cows (within 3 wk postpartum) with similar lactation numbers (median $=3$, range $=2-4$ ) and days in milk (median $=6$, range $=3-15$ ) were classified based on serum $\beta$-hydroxybutyrate (BHB) level as control $(\mathrm{n}=15, \mathrm{BHB}<0.6 \mathrm{~m} M)$ or SCK $(\mathrm{n}=$ $15,1.2 \mathrm{~m} M<$ BHB $<3.0 \mathrm{~m} M)$. Cows with SCK had greater levels of serum haptoglobin, serum amyloid A, IL-1 $\beta$, IL-6, IL-8 and tumor necrosis factor- $\alpha$. These proinflammatory factors had strong positive correlations with myeloperoxidase (MPO), a marker protein of PMN AG, whose content was greater in the serum of SCK cows. Both the number of AG and the protein abundance of MPO were lower in PMN isolated from SCK cows. Additionally, we found a greater ratio of blood $\mathrm{CH} 138 \mathrm{~A}^{+} / \mathrm{CD} 63^{\text {high }}$ cells and greater mean fluorescence intensity of CD63 on the PMN membrane, further confirming the greater degree of AG degranulation in cows with SCK. In vitro FFA dose response $(0,0.3$, $0.6,1.2$, and $2.4 \mathrm{~m} M$ for $4 \mathrm{~h})$ and time course $(0,0.5,1$, 2 , and $4 \mathrm{~h}$ with $0.6 \mathrm{mM}$ ) experiments were performed on PMN isolated from control cows. The increase in MPO content in extracellular supernatant resulting
\end{abstract}

\footnotetext{
Received July 30, 2021.

Accepted December 6, 2021.

*These authors contributed equally to this work.

†Corresponding author: liuguowen2008@163.com
}

from those experiments led to the selection of $0.6 \mathrm{~m} M$ FFA for $1 \mathrm{~h}$ duration as conditions for subsequent studies. After FFA treatment, release of intracellular MPO was increased along with increased levels of CD63 mean fluorescence intensity on the PMN membrane, confirming that FFA promoted degranulation of AG. In addition, FFA treatment increased reactive oxygen species (ROS) production by PMN, an effect that was attenuated by incubation with diphenyleneiodonium chloride (DPI), a NADPH oxidase-derived ROS inhibitor. The mitochondrial-derived ROS inhibitor carbonyl cyanide 4-(trifluoromethoxy) phenylhydrazone (FCCP) did not affect ROS in response to FFA treatment. Treatment with FFA increased p47 phosphorylation and mRNA abundance of NCF1, NCF2, and $C Y B B$ in PMN. Furthermore, DPI, but not FCCP, dampened the degranulation of PMN AG induced by FFA in vitro. These data suggested that the degranulation of AG in PMN induced by FFA was mediated by NADPH oxidase-derived ROS. As verified ex vivo, PMN from SCK cows had greater levels of ROS, phosphorylation of p47, and mRNA abundance of NCF1, NCF2, and $C Y B B$. Overall, the present study revealed that high blood concentrations of FFA in SCK cows induce the production of NADPH oxidase-derived ROS, thereby promoting degranulation of AG in PMN. The stimulatory effect of FFA on the release of AG content during degranulation, especially MPO, provides a new insight into the systemic inflammation experienced by peripartal cows with SCK.

Key words: dairy cows, subclinical ketosis, free fatty acids, neutrophil, degranulation

\section{INTRODUCTION}

Peripartal dairy cows are in a state of negative energy balance that leads to excessive fat mobilization and a marked increase in concentrations of free fatty 
acids (FFA) in circulation (Martens, 2020). Incomplete metabolism of FFA in the liver leads to production of ketone bodies and ketosis. By increasing the expense of diagnosis, treatment, milk losses, the probability of death, and early culling, ketosis shrinks the profit of the dairy industry (Martens, 2020). Onset of ketosis also causes a significant increase in the incidence rate of other inflammatory diseases such as mastitis, endometritis, and laminitis (Suthar et al., 2013).

Subclinical ketosis (SCK) is defined as an excess of circulating ketone bodies without clinical signs (Brunner et al., 2019). Average prevalence of SCK is around $24.1 \%$, which is higher than that of clinical ketosis, thereby responsible for greater losses in earnings (Brunner et al., 2019). Cows with SCK also experience systemic inflammation, which is characterized by enhanced blood levels of proinflammatory cytokines and acute-phase proteins (Abuajamieh et al., 2016). The systemic inflammation during SCK is closely related to the reduction in production performance and welfare (Brunner et al., 2019; Vallejo-Timarán et al., 2020). The underlying mechanism responsible for systemic inflammation in dairy cows with SCK needs further clarification.

Polymorphonuclear neutrophils account for a high proportion of blood leukocytes and serve as the frontline of immune defense. Although PMN play a proinflammatory role by increasing the release of inflammatory mediators, if they become dysfunctional, their activity could contribute to excessive local and systemic inflammation (Daha, 2011). Free fatty acids have been shown to increase the synthesis of proinflammatory cytokines in PMN of SCK dairy cows (Zhang et al., 2018). High plasma FFA in obese and diabetic humans have also been found to be associated with increased plasma levels of myeloperoxidase (MPO) (Mathew et al., 2010). This enzyme is one of the most important proteases stored in the azurophil granules (AG) of PMN and acts as a versatile proinflammatory factor after its extracellular release through the degranulation process (Aratani, 2018). Work from one of our laboratories has revealed that peripartal cows fed higher-energy diets during the dry period had a 3.5-fold upregulation in blood MPO, an effect that was associated with increased blood FFA in those cows (Moyes et al., 2014). The data suggested a potentially close relationship between FFA and AG degranulation of PMN. The exact effects and the underlying mechanisms whereby elevated blood FFA could affect the degranulation of AG in PMN from dairy cows are still unknown.

In phagocytes, reactive oxygen species (ROS) from respiratory burst not only kill bacteria but also act as signal molecules to transmit intracellular information, including proinflammatory signaling (D'Autréaux and
Toledano, 2007). Production of ROS from respiratory burst is mainly mediated by NADPH oxidase (Lam et al., 2010). In PMN, the phosphorylation of $\mathrm{p} 47$ promotes the binding of cytoplasmic p47, p67, and p40 with membrane gp91 and p22 to complete the assembly of NADPH oxidase (El-Benna et al., 2016). In human and mouse studies, elevated blood FFA increased NADPH oxidase-derived ROS production in PMN, which was proposed to contribute to the overt inflammatory state associated with metabolic diseases such as atherosclerosis and diabetes (Guerra and Otton, 2011; El-Benna et al., 2016).

Given the potential role of FFA on NADPH oxidase activation and AG degranulation, we speculated that NADPH oxidase-derived ROS in response to elevated FFA may mediate the release of AG from PMN of dairy cows. Thus, our general hypothesis was that FFA enhance AG degranulation via promoting NADPH oxidase-derived ROS production in PMN of SCK cows. The overall objective of this study was to explore the effects of FFA on AG degranulation of PMN and the underlying mechanisms.

\section{MATERIALS AND METHODS}

\section{Animals and Sampling}

The protocol was approved by the Ethics Committee on the Use and Care of Animals of Jilin University (No. SY202012017; Changchun, China). In the current study, experimental animals received humane care according to the principles and guidelines of the Guidelines for the Care and Use of Agricultural Animals in Research and Teaching, 3rd ed (FASS Inc., 2010). The design of this study used a case-control strategy, and the selection and treatment of experimental animals in the present study were similar to those of our previous studies (Song et al., 2021). In brief, based on a nitroprusside test for milk ketone bodies, we screened out 24 suspected SCK and 24 control cows of similar parity $($ median $=3$, range $=2-4)$ and DIM (median $=6 \mathrm{~d}$, range $=3-15 \mathrm{~d}$ ) from 100 lactating Holstein cows in a dairy farm located in Changchun City, Jilin Province, China. All screened cows received a routine physical examination to ensure absence of clinical symptoms and comorbidities. Screened cows were milked twice daily at $0800 \mathrm{~h}$ and $1530 \mathrm{~h}$. Average milk yield over 3 consecutive days was calculated. Serum BHB concentrations were used to confirm ketosis, resulting in 20 SCK $(1.2<\mathrm{BHB}<3 \mathrm{mmol} / \mathrm{L})$ and 22 control $(\mathrm{BHB}<1.2 \mathrm{mmol} / \mathrm{L})$ cows. Notably, all selected SCK cows were cases of reduced milk production compared with the average of the control cows. Assessment of the appropriate number of cows in each group was 
calculated according to a sample size calculation tool (https://www.bu.edu/researchsupport/compliance/ animal-care/working-with-animals/research/sample -size-calculations-iacuc). In brief, the pre-experimental data revealed that the standard deviation of MPO (a marker of AG) protein abundance was approximately 0.3 , and we aimed to be able to detect a 0.5 -fold difference in relative MPO abundance between control cows and SCK cows with $P=0.01$ and a $95 \%$ power. Accordingly, at least 13 cows in each group were required. To account for any inadvertent losses, we included 2 additional cows in each group. Thus, the final cohort contained 15 cows in each group. All selected cows were housed in a climate-controlled barn (daily air temperature $10-20^{\circ} \mathrm{C}$ ) with individual tiestalls, to reduce environmental interference. Cows had ad libitum access to the same diet, and fresh water was supplied continuously. The average DMI for each group was calculated based on feed fed and refused during 3 consecutive days, as described previously (Song et al., 2021).

Blood samples were collected from the jugular vein at 0630 to $0730 \mathrm{~h}$, before feeding, for 5 consecutive days. To obtain serum, blood samples were kept for $30 \mathrm{~min}$ at room temperature and then centrifuged at $4^{\circ} \mathrm{C}$ for 3,000 $\times g$ for $15 \mathrm{~min}$ and stored at $-80^{\circ} \mathrm{C}$ immediately until use. Serum glucose, BHB, and FFA were detected using commercially available kits (glucose, Cat. No. GL3815; BHB, Cat. No. RB1008; FFA, Cat. No. FA115; Randox Laboratories) using a Hitachi 7170 autoanalyzer. Serum metabolic indices, together with DMI and milk production for the selected control and SCK cows, are reported in Table 1.

\section{Detection of Serum Inflammatory Factors}

Concentrations of haptoglobin (HP) and serum amyloid A (SAA) were determined with bovine-specific ELISA kits (HP, LS-F13229; SAA, LS-F12552, LifeSpan BioSciences Inc.) according to the manufacturer's instructions. Kit sensitivity for HP and SAA was $7.8 \mathrm{ng} /$ $\mathrm{mL}$ and $3.12 \mathrm{ng} / \mathrm{mL}$, respectively. Intra- and interassay

Table 1. Basic description of the selected control cows and cows with subclinical ketosis $(\mathrm{SCK})^{1}$

\begin{tabular}{lrrr}
\hline Item & $\begin{array}{c}\text { Control } \\
(\mathrm{n}=15)\end{array}$ & $\begin{array}{c}\text { SCK } \\
(\mathrm{n}=15)\end{array}$ & $P$-value \\
\hline Milk yield (kg/cow per day) & $29.96 \pm 0.82$ & $23.46 \pm 0.56$ & $<0.01$ \\
DMI (kg/d) & $22.64 \pm 0.26$ & $21.18 \pm 0.15$ & $<0.01$ \\
Serum BHB $(\mathrm{m} M)$ & $0.36 \pm 0.02$ & $1.83 \pm 0.08$ & $<0.01$ \\
Serum FFA $(\mathrm{m} M)$ & $0.26 \pm 0.02$ & $0.58 \pm 0.03$ & $<0.01$ \\
Serum glucose $(\mathrm{m} M)$ & $4.38 \pm 0.05$ & $2.97 \pm 0.04$ & $<0.01$ \\
\hline
\end{tabular}

${ }^{1}$ Values are shown as means \pm SEM. $P<0.05$ was considered significant and $P<0.01$ highly significant. FFA $=$ free fatty acids. coefficients of variation (CV) for HP and SAA were less than $6.5 \%$ and $8.8 \%$, and $10 \%$ and $12 \%$, respectively. Concentrations of IL-1 $\beta$, IL-6, IL-8, and tumor necrosis factor- $\alpha(\mathrm{TNF}-\alpha)$ were measured with bovine-specific ELISA kits (IL-1 $\beta$, LS-F7588; IL-6, LS-F9752; IL-8, LSF6143; TNF- $\alpha$, LS-F5014; LifeSpan BioSciences Inc.) according to the manufacturer's instructions. Kit sensitivity of IL-1 $\beta$, IL-6, IL-8, and TNF- $\alpha$ was $6.5 \mathrm{pg} / \mathrm{mL}$, $0.46 \mathrm{pg} / \mathrm{mL}, 26.1 \mathrm{pg} / \mathrm{mL}$, and $3.1 \mathrm{pg} / \mathrm{mL}$, respectively. Intra- and interassay CV for IL-1 $\beta$, IL-6, IL-8, and TNF- $\alpha$ were all less than $10 \%$ or $12 \%$. Concentration of MPO was determined with a bovine-specific ELISA kit (LS-F6445, LifeSpan BioSciences Inc.) according to the manufacturer's instructions. Kit sensitivity of MPO was $0.64 \mathrm{ng} / \mathrm{mL}$. Intra- and interassay $\mathrm{CV}$ for MPO were less than $10 \%$ or $12 \%$. Correlations between the content of serum MPO and HP, SAA, IL-13, IL-6, IL-8, and TNF- $\alpha$ in serum were analyzed with the Spearman method.

\section{Isolation, Culture, and Treatment of PMN}

Blood was collected from the jugular vein using an evacuated blood collection tube (YA1393, Solarbio Science and Technology Co. Ltd.) with acid citrate dextrose and kept at room temperature until transported to the laboratory (within 30 min after collection). The PMN were isolated using a commercial bovine peripheral blood PMN isolation kit (P9400, Solarbio Science and Technology Co. Ltd.) according to the manufacturer's instructions. In brief, PMN were separated based on the density gradient centrifugation method. Erythrocyte lysis buffer (R1010, Solarbio Science and Technology Co. Ltd.) was added to remove red blood cells, followed by washing the remaining cells twice with RPMI-1640 (Cat. No. SH30809.01, Hyclone Laboratories) and centrifuged for $10 \mathrm{~min}$ at $500 \times g$ to harvest PMN. The separation system was kept at room temperature to eliminate the influence of temperature change on the activity of PMN. The isolated PMN underwent Giemsa staining (G1020, Solarbio Science and Technology Co. Ltd.) to confirm purity and a trypan blue dye exclusion test (C0040, Solarbio Science and Technology Co. Ltd.) to determine their viability. Purity of the obtained PMN was $\sim 97.5 \%$ with $\sim 95 \%$ viability.

For ex vivo experiments, isolated PMN of SCK and control cows were directly used for the following experiments. For in vitro experiments, PMN were resuspended in basal culture medium containing $10 \%$ fetal bovine serum (SH30084, Hyclone Laboratories) and 1\% penicillin-streptomycin (Sv30010, Hyclone Laboratories) in RPMI medium (SH30809.01, Hyclone Laboratories). After cell counting, the cell suspension was 

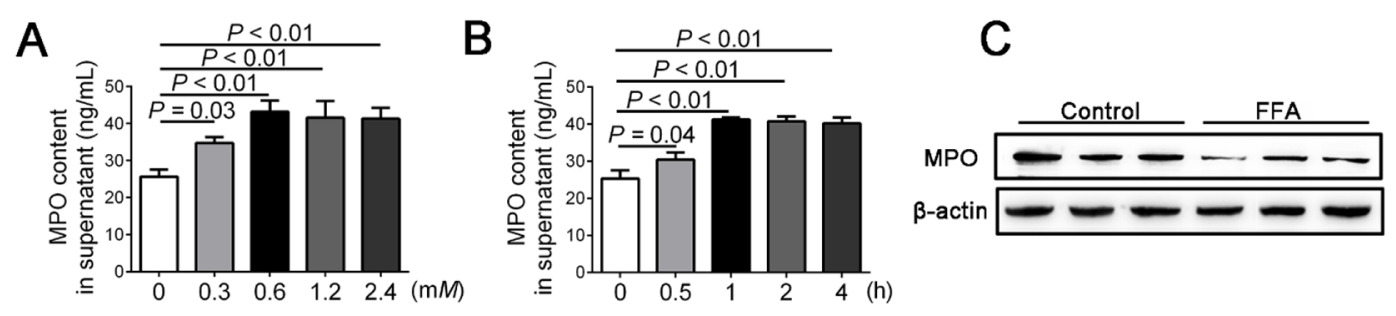

D

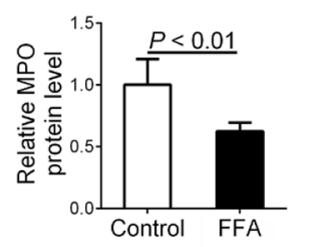

$\mathrm{E}$
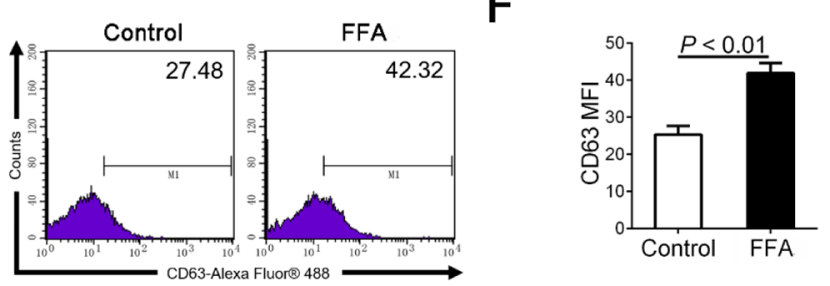

Figure 1. Effects of free fatty acids (FFA) on azurophil granule (AG) degranulation of bovine PMN in vitro. (A) Content of myeloperoxidase (MPO) released to the supernatant during PMN degranulation after different concentrations of FFA treatment for $4 \mathrm{~h}$. (B) Content of MPO released to the supernatant during PMN degranulation after different times of FFA treatment at $0.6 \mathrm{~m} M$. Accordingly, PMN treated with 0.6 $\mathrm{m} M$ FFA for $1 \mathrm{~h}$ were selected for the experimental conditions in the following experiments. (C) Protein levels of intracellular MPO in PMN with or without FFA treatment. Three wells of each group represent 3 samples from different experiments, respectively. (D) Quantification of MPO protein levels in C. (E) Representative CD63 fluorescence intensity in PMN with or without FFA treatment. The fluorescence intensity values of the representative graphs of each group are shown in the upper right corner. (F) Quantification of CD63 mean fluorescence intensity (MFI) in the PMN with or without FFA treatment (FFA, $0.6 \mathrm{mM}, 1 \mathrm{~h}$ ). Data were analyzed with a one-way ANOVA with subsequent Bonferroni correction or independent-samples $t$-tests. Data are expressed as mean \pm SEM. $P<0.05$ is considered significant and $P<0.01$ as highly significant.

adjusted to $1 \times 10^{6}$ cells $/ \mathrm{mL}$ and seeded in 24 -well cell culture plates. Then PMN were incubated for 30 min at $37^{\circ} \mathrm{C}$ with a humidified atmosphere and $5 \% \mathrm{CO}_{2}$.

The FFA mixture was prepared according to a published protocol (Contreras et al., 2012; Liu et al., 2014). In brief, to make the FFA stock, individual FFA were diluted in $0.1 \mathrm{M} \mathrm{KOH}$ at $65^{\circ} \mathrm{C}$ and adjusted to $\mathrm{pH} 7.4$ with $1 \mathrm{M} \mathrm{HCl}$. This FFA stock $(52.7 \mathrm{mM})$ consisted of $22.9 \mathrm{~m} M$ oleic acid (C18:1n-9), $2.6 \mathrm{~m} M$ linoleic acid (C18:2n-6), $16.8 \mathrm{~m} M$ palmitic acid (C16:0), $7.6 \mathrm{mM}$ stearic acid (C18:0), and $2.8 \mathrm{~m} M$ palmitoleic acid (C16: 1n-7). This FFA stock was then diluted in cell medium supplemented with $2 \%$ fatty acid-free BSA (A2000, Applygen Tech) to obtain target concentrations. Concentrations of FFA in vitro were selected according to a previous study (Duffield et al., 2009; Borchardt and Staufenbiel, 2012). The PMN were maintained in RPMI1640 medium for $30 \mathrm{~min}$, followed by FFA treatment $(0,0.3,0.6,1.2$, and $2.4 \mathrm{~m} M)$ for $4 \mathrm{~h}$. The $0.6 \mathrm{~m} M \mathrm{FFA}$ treatment for $4 \mathrm{~h}$ had an obvious effect on supernatant MPO content released by bovine PMN. Thus, $0.6 \mathrm{mM}$ FFA was selected as the dose to challenge PMN for 0 , 0.5, 1, 2, and $4 \mathrm{~h}$. Treatment with FFA for $1 \mathrm{~h}$ had an obvious effect on supernatant MPO content released by bovine PMN (Figure 1A and B). Thus, $0.6 \mathrm{mM}$ FFA for $1 \mathrm{~h}$ was selected for subsequent experiments. To verify the source of ROS production induced by FFA and their role in the degranulation of PMN, NADPH oxidase-derived ROS inhibitor diphenyleneiodonium chloride (DPI, $10 \mu M$, Cat. No. 4673-26-1, Selleck) and mitochondria-derived ROS inhibitor carbonyl cyanide 4-(trifluoromethoxy) phenylhydrazone (FCCP, $10 \mu \mathrm{M}$, Cat. No. 370-86-5, Selleck) were preincubated with PMN for $0.5 \mathrm{~h}$ before treatment with FFA.

\section{Protein Extraction and Western Blotting}

Western blotting was performed as described previously (Song et al., 2016). In brief, protein was extracted from PMN using a commercial Protein Extraction Kit (C510003, SANGON Biotechnology Co. Ltd.) according to the manufacturer's instructions. Protein concentration was measured via the Pierce bicinchoninic acid method (P1511, Applygen Technologies). A total of $30 \mu \mathrm{g}$ of protein from each sample was separated by $12 \%$ SDS PAGE. The target protein on the gel was transferred to 0.45- $\mu \mathrm{m}$ polyvinylidene difluoride membranes (PVDF, YA1701, Solarbio Science and Technology Co. Ltd.). The PVDF membranes were blocked with Tris-buffered saline solution with 0.1\% Tween-20 (T8220, Solarbio Science and Technology Co. Ltd.) and 3\% BSA (A8850, Solarbio Science and Technology Co. Ltd.) for $2 \mathrm{~h}$ at room temperature. After electrophoresis, transfer, and blocking, immunoblots were performed using primary $\beta$-actin (1:2,000; Ab8226, Abcam), MPO (1:500; LSC663612-100, LifeSpan BioSciences Inc.), p47 (1:1,000; AF5220, Affinity Biosciences), and phosphorylated (p)p47 (1:1,000; YP1018, Immunoway Biotechnology) at $4^{\circ} \mathrm{C}$ overnight, respectively. Subsequently, the PVDF membranes were washed 3 times with Tris-buffered 
saline solution (TBST) with $0.1 \%$ Tween-20 and incubated with horseradish peroxidase-conjugated antimouse (1:5,000; SA00001-1, ProteinTech Group Inc.) or anti-rabbit antibodies (1:5,000; SA00001-2, ProteinTech Group Inc.) for $45 \mathrm{~min}$ at room temperature. After washing the PVDF membranes another 3 times with TBST, immunoreactive bands were visualized by enhanced chemiluminescence solution (WBKLS0500, Millipore). $\beta$-Actin was used as a reference protein, and the phosphorylation level of $\mathrm{p} 47$ was calculated as p-p47/total p47. Finally, all bands were imaged using a Protein Simple Imager (ProteinSimple). All protein bands were analyzed using Image-Pro Plus 6.0 (Media Cybernetics Inc.).

\section{Transmission Electron Microscopy}

The number of AG in cells was evaluated by transmission electron microscope (H-7650 electron microscope, Hitachi). Isolated PMN were fixed with $2.5 \%$ glutaraldehyde and $2 \%$ paraformaldehyde at $4^{\circ} \mathrm{C}$ for 12 $\mathrm{h}$ and then postfixed in 1\% osmium tetroxide for $1 \mathrm{~h}$. Subsequently, samples were dehydrated in an ethanol series $(70 \%, 80 \%, 90 \%, 100 \%, 100 \%$, and $100 \%)$ and infiltrated with Spurr's resin. Ultra-thin sections (50 $\mathrm{nm}$ ) were cut and stained with $4 \%$ uranyl acetate and $0.2 \%$ lead citrate. Observations were performed in a transmission electron microscope. The AG were counted from at least 15 random cell sections in each sample and expressed as the average number per cell section (Song et al., 2016).

\section{Determination of Degranulation of AG in PMN}

For ex vivo experiments, after removal of red blood cells with erythrocyte lysis buffer (R1010, Solarbio Science and Technology Co. Ltd.), the remaining leukocytes were fixed with $4 \%$ paraformaldehyde for $20 \mathrm{~min}$ at room temperature. According to a previous study (Depreester et al., 2017), cells were incubated with anti-bovine granulocyte monoclonal antibody (clone CH138A, 1:100; WSC0608B-100, Kingfisher Biotech), a specific cow PMN marker, and CD63 antibody (1:100; ABIN6254234, Antibodies Online $\mathrm{GmbH}$ ), a specific AG marker, for 30 min, followed by washing with cold PBS twice. Subsequently, cells were incubated with PE-conjugated anti-mouse (1:200; I1903-12X-500 $\mu \mathrm{g}$, United States Biological) and Alexa Fluor 488-conjugated anti-goat immunoglobulin (1:200; A-11055, Thermo Fisher Scientific), and FITC-conjugated CD11b antibody (1:200; NB110-89474F, Novus Biologicals) for 30 min, followed by washing the cells with cold PBS twice. Finally, flow cytometry (FACSCalibur, Becton Dickinson) was used to detect the degranulation of
AG through measuring the level of membrane CD63 (a marker of AG degranulation) in PMN. For in vitro experiments, isolated PMN from bovine blood were incubated with CD63 antibody (1:100; ABIN6254234, Antibodies Online $\mathrm{GmbH}$ ) for $30 \mathrm{~min}$, and washed with cold PBS twice. Subsequently, cells were incubated with Alexa Fluor 488-conjugated anti-goat immunoglobulin for $30 \mathrm{~min}$, followed by washing the cells with cold PBS twice. Flow cytometry was used to detect the level and proportion of degranulation of AG in PMN.

\section{Determination of Intracellular ROS Concentration}

After FFA treatment, PMN were incubated with dichlorofluorescein diacetate (S0033S, Beyotime Biotechnology Inc.) for $30 \mathrm{~min}$ at $37^{\circ} \mathrm{C}$. Fluorescence intensity of the PMN was measured by flow cytometry (FACSCanto II, Becton Dickinson) according to the manufacturer's instructions. For ex vivo experiments, intracellular ROS determination was performed in triplicate for each sample ( $\mathrm{n}=15$ cows per group). For in vitro experiments, determination was performed from each of the 3 individual cell preparations.

\section{Quantitative Reverse-Transcription PCR Assay}

Quantitative reverse-transcription PCR was performed as described previously (Song et al., 2021). Total RNA from PMN was extracted using Trizol (15596026, Invitrogen). A Nanophotometer N50 Touch (Implen $\mathrm{GmbH}$ ) was used to measure RNA concentration. In accordance with MIQE guidelines (Bustin et al., 2009), an optical density (OD) of 1.8 to 2.0 is a suitable threshold for assessing RNA quality using the ratio of $\mathrm{OD}$ at $260 \mathrm{~nm}$ to $\mathrm{OD}$ at $280 \mathrm{~nm}$. The OD260:OD280 ratio of RNA samples in the present study ranged from 1.88 to 1.97 . Gel electrophoresis $(1 \%$ agarose gels) showed clear $18 \mathrm{~S}$ and $28 \mathrm{~S}$ bands without significant degradation, with the $28 \mathrm{~S}$ rRNA band being approximately twice as intense as the $18 \mathrm{~S}$ rRNA band. A PrimeScript Reverse Transcriptase Kit (6110B, TaKaRa Biotechnology Co. Ltd.) was used with $1 \mu \mathrm{g}$ of total RNA to reverse-transcribe into cDNA according to the supplier's protocol. Reverse-transcription PCR was performed in a $20-\mu \mathrm{L}$ volume on 96 -well clear plates using the SYBR Green Plus Reagent Kit (RR420A, TaKaRa Biotechnology Co. Ltd.) on a 7500 Real-Time PCR System (Applied Biosystems Inc.).

Conditions used for PCR experiments were as follows: $95^{\circ} \mathrm{C}$ for $3 \mathrm{~min}$, followed by 40 cycles of $95^{\circ} \mathrm{C}$ for $15 \mathrm{~s}$, and $60^{\circ} \mathrm{C}$ for $1 \mathrm{~min}$. Gene expression was calculated with the $2^{-\Delta \Delta \mathrm{CT}}$ method, where $\mathrm{CT}$ is the cycle threshold. Genes of interest were normalized to the geometrical mean of $\mathrm{CT}$ values of $\beta$-actin and YWHAZ 
Table 2. The primer sequences used for quantitative real-time $\mathrm{PCR}^{1}$

\begin{tabular}{|c|c|c|c|}
\hline Gene & Sequence number & Primer sequences $\left(5^{\prime}-3^{\prime}\right)$ & Length (bp) \\
\hline$C Y B B(\operatorname{gp} 91)$ & NM_174035.4 & $\begin{array}{l}\text { FOR: CTCGAAAACTTCTTGGGTCAGC } \\
\text { REV: AGGTGAGGTTCCTGTCCAGT }\end{array}$ & 174 \\
\hline$C Y B A(\mathrm{p} 22)$ & NM_174034.2 & $\begin{array}{l}\text { FOR: CTGGCGTCCGGTCTAATCCT } \\
\text { REV: TCCAGCAGGCAGACCAATAC }\end{array}$ & 116 \\
\hline NCF2 (p67) & NM_174120.2 & $\begin{array}{l}\text { FOR: CTGACGCTGTGGTGTGAGAA } \\
\text { REV: CCAGCCATTGTTCATTCACCGT }\end{array}$ & 223 \\
\hline$N_{C F} 4(\mathrm{p} 40)$ & NM_001045983.1 & $\begin{array}{l}\text { FOR: AGCCAAAGTCTACGTGGGTG } \\
\text { REV: GCTGAGGAGGTGCTTCATGT }\end{array}$ & 85 \\
\hline
\end{tabular}

${ }^{1}$ The corresponding protein name is shown in parentheses after the gene symbol. FOR $=$ forward; REV $=$ reverse.

(Zhang et al., 2005; De Ketelaere et al., 2006). For ex vivo quantitative reverse-transcription PCR experiments, the PCR reaction was performed in triplicate for each sample ( $\mathrm{n}=15$ cows per group). For in vitro quantitative reverse-transcription PCR experiments, the PCR reactions were performed from each of the 3 individual cell preparations. The primers of target genes, as shown in Table 2, were designed by Primer Express software 5.0 (Thermo Fisher Scientific).

\section{Statistical Analysis}

All experiments were repeated at least 3 times. Linear and quadratic contrasts were conducted to evaluate dose- and time-dependent effects. The 2-way ANOVA was used when there were 2 treatment factors (FFA and DPI; FFA and FCCP), including a Bonferroni post-hoc analysis when significant interaction occurred. The one-way ANOVA with subsequent Bonferroni correction or independent-samples $t$-tests was used when there was only 1 treatment factor. Correlation analysis was performed using the Spearman method. Weak, moderate, and strong correlations were defined as correlation coefficients (r) of 0 to $0.39,0.40$ to 0.59 , and 0.6 to 1.0, respectively. Other non-normally distributed data were analyzed with Wilcoxon signed-rank test. All analyses were performed using GraphPad Prism 8.0 (Graph Pad Software).

\section{RESULTS}

\section{Baseline Characteristics of SCK Cows}

As shown in Table 1, compared with the control group, cows in the SCK group had lower DMI and milk yield $(P<0.01)$. Serum BHB and FFA increased $(P$ $<0.01)$ in SCK cows. Conversely, serum glucose was lower in SCK cows $(P<0.01)$.

\section{Enhanced Systemic Inflammation of SCK Cows}

Compared with the control group, cows in the SCK group had greater $(P<0.01)$ concentrations of HP and SAA in serum (Figure 2A and B). The SCK cows had increased $(P<0.01)$ concentrations of serum proinflammatory cytokines, including IL-1 $\beta$, IL-6, IL-8, and TNF- $\alpha$ (Figure $2 \mathrm{C}-\mathrm{F}$ ), coupled with elevated concentrations of MPO $(P<0.01 ;$ Figure $2 \mathrm{G})$. We found that HP, SAA, IL-1 $\beta$, IL-6, IL-8, and TNF- $\alpha$ each had strong positive correlations with MPO (Table 3).

\section{Elevated Degranulation of AG in PMN of SCK Cows}

Compared with the control group, the PMN isolated from the blood of SCK cows had lower abundance of intracellular MPO protein $(P<0.01$; Figure $3 \mathrm{~A}$ and B). Consistently, as detected by transmission electron microscope, SCK cows had fewer AG $(P<0.01$; Figure $3 \mathrm{C}$ and $\mathrm{D})$. Additionally, as detected by flow cytometry, SCK cows had a greater percentage of $\mathrm{CH} 138 \mathrm{~A}^{+} /$ CD63 ${ }^{\text {high }}$ PMN $(P<0.01$; Figure $3 \mathrm{E}$ and F $)$. Similarly, the mean fluorescence intensity of CD63 (a marker of AG degranulation) was elevated in PMN of SCK cows $(P<0.01 ;$ Figure $3 \mathrm{G})$.

\section{FFA Induce Degranulation of AG in Bovine PMN In Vitro}

Bovine PMN were treated with FFA $(0,0.3,0.6,1.2$, or $2.4 \mathrm{mM})$ for $4 \mathrm{~h}$ in vitro. We found a linear increase $(P<0.01)$ and a quadratic effect $(P<0.01)$ for MPO content in supernatant due to increased dose of FFA, with a peak response at $0.6 \mathrm{~m} M(P<0.01$; Figure $1 \mathrm{~A})$. Subsequently, bovine PMN were treated with FFA (0.6 $\mathrm{m} M$ ) for $0,0.5,1,2$, or $4 \mathrm{~h}$ in vitro. We observed a linear increase $(P<0.01)$ and quadratic effect $(P<0.01)$ for MPO content in supernatant due to the increased 

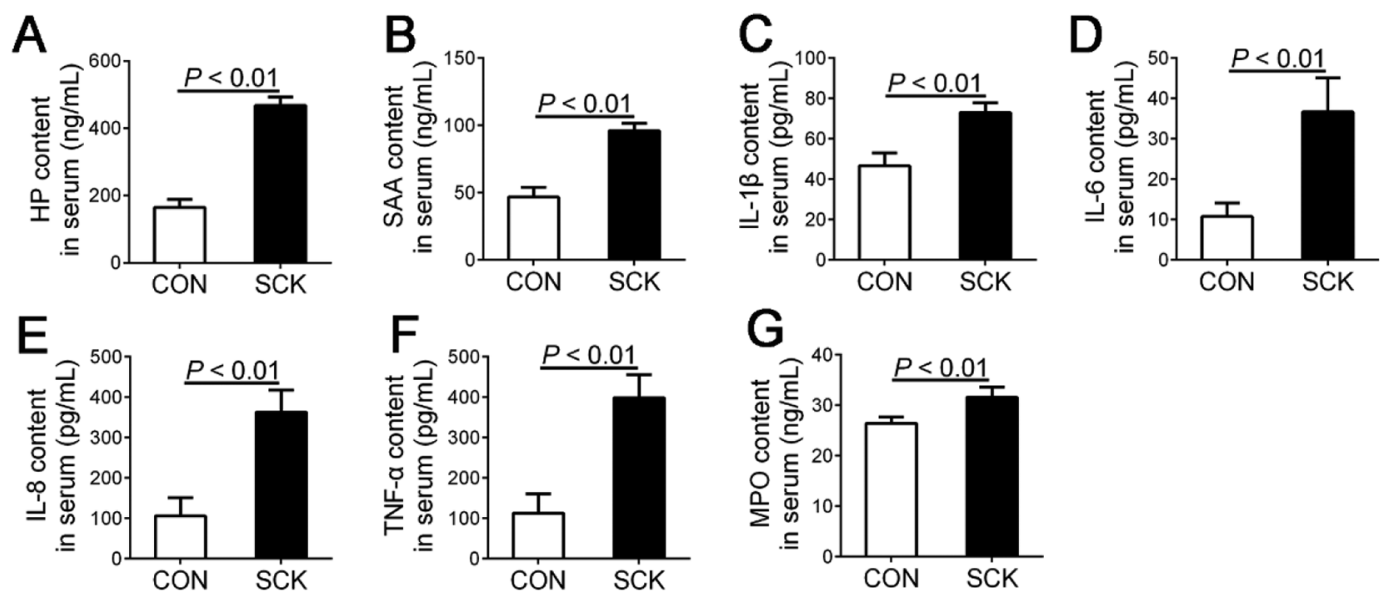

Figure 2. State of systemic inflammation of control cows $(\mathrm{CON} ; \mathrm{n}=15)$ and cows with subclinical ketosis $(\mathrm{SCK} ; \mathrm{n}=15)$. (A, B) Contents of HP and SAA in serum. (C-F) Contents of IL-13, IL-6, IL-8, and TNF- $\alpha$ in serum. (G) Content of myeloperoxidase (MPO) in serum. Data were analyzed with independent-samples $t$-tests. All data are expressed as mean \pm SEM. $P<0.05$ is considered significant and $P<0.01$ as highly significant. $\mathrm{HP}=$ haptoglobin; SAA = serum amyloid $\mathrm{A}$; TNF- $\alpha=$ tumor necrosis factor- $\alpha$.

time during stimulation, with a peak response at $1 \mathrm{~h}$ $(P<0.01 ;$ Figure 1B). Thus, $0.6 \mathrm{~m} M$ FFA for $1 \mathrm{~h}$ was selected as the treatment conditions in subsequent experiments. The protein abundance of intracellular MPO decreased in bovine PMN after treatment with FFA $(P$ $<0.01$; Figure 1C and D). In agreement, CD63 mean fluorescence intensity was greater after FFA treatment $(P<0.01 ;$ Figure $1 \mathrm{E}$ and $\mathrm{F})$.

\section{NADPH Oxidase-Derived ROS Mediates FFA-Induced Degranulation of AG in Bovine PMN In Vitro}

Compared with the control group, FFA treatment increased ROS production of bovine PMN as detected by flow cytometry, which was reversed by DPI $(P<$ 0.01 ), a specific inhibitor of NADPH oxidase-derived ROS production, but not by FCCP, a specific inhibitor of mitochondria-derived ROS production (Figure 4A and B). Additionally, phosphorylation of $\mathrm{p} 47$, the key functional component of NADPH oxidase, increased in bovine PMN after FFA treatment $(P<0.05$; Figure $4 \mathrm{C}$ and D). The mRNA abundance of NCF1 (p47), NCF2 (p67), and $C Y B B$ (gp91) increased after FFA treatment of PMN, but no significant difference was detected for $N_{4 F}$ (p40) and CYBA (p22; Figure 4E-I). Additionally, DPI, but not FCCP, significantly attenuated the effect of FFA on the protein abundance of intracellular MPO in PMN (Figure 5A and B). Also, DPI, but not FCCP, markedly alleviated the increase of membrane CD63 level induced by FFA challenge on PMN (Figure $5 \mathrm{C}$ and $\mathrm{D})$.

\section{SCK Cows Have Enhanced Activation of NADPH Oxidase-ROS Pathway in PMN}

As detected by flow cytometry, compared with the control group, the PMN of SCK cows had a greater level of $\operatorname{ROS}(P<0.01$; Figure $6 \mathrm{~A}$ and $\mathrm{B})$. Additionally, phosphorylation of $\mathrm{p} 47$ protein was elevated in the PMN of SCK cows $(P<0.05$; Figure $6 \mathrm{C}$ and D). Consistent with in vitro experiments, the abundances of $N C F 1$ (p47), NCF2 (p67), and CYBB (gp91) were greater in SCK cows $(P<0.01$; Figure $6 \mathrm{E}, \mathrm{F}$, and $\mathrm{H})$. No significant difference was detected for mRNA

Table 3. Correlation analysis (r-values) and $P$-values (in parentheses below r-values) between proinflammatory factors and myeloperoxidase $(\mathrm{MPO})$ in serum $^{1}$

\begin{tabular}{lcccccc}
\hline & \multicolumn{5}{c}{ Proinflammatory factor } \\
\cline { 2 - 6 } Item & HP & SAA & IL-1 $\beta$ & IL-6 & IL-8 & TNF- $\alpha$ \\
\hline MPO & 0.7455 & 0.6970 & 0.6848 & 0.7576 & 0.7697 & 0.8909 \\
& $(0.0174)$ & $(0.0306)$ & $(0.0347)$ & $(0.0149)$ & $(0.0126)$ & $(<0.01)$ \\
\hline
\end{tabular}

${ }^{1}$ Weak, moderate, and strong correlations were defined as correlation coefficients (r) of $0-0.39,0.40-0.59$, and $0.6-1.0$, respectively. $P<0.05$ was considered significant and $P<0.01$ highly significant. HP $=$ haptoglobin; SAA = serum amyloid A; TNF- $\alpha=$ tumor necrosis factor- $\alpha$. 
abundances of NCF4 (p40) and CYBA (p22) between the control and SCK groups (Figure $6 \mathrm{G}$ and I).

\section{DISCUSSION}

Subclinical ketosis in peripartal dairy cows, a core energy metabolism disorder disease, is accompanied by systemic inflammation (Abuajamieh et al., 2016). The pathogenesis of this systemic inflammation is unclear. The present study confirmed that SCK cows experience systemic inflammation. As suggested by the strong positive correlations between the content of serum proinflammatory factors and MPO, a marker protein of PMN AG, our ex vivo data uncovered that PMN in SCK cows exhibited an increase in AG degranulation. Our in vitro data further revealed that FFA mediate
A

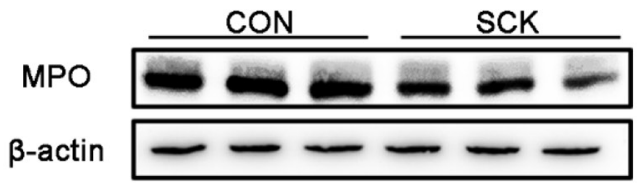

C

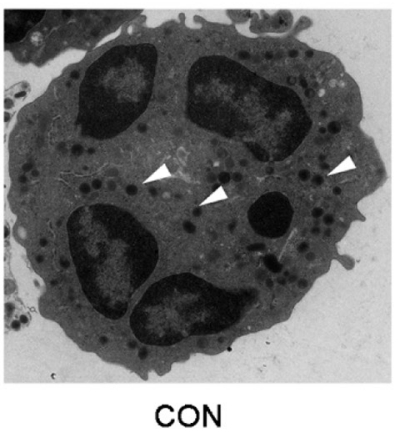

$E$
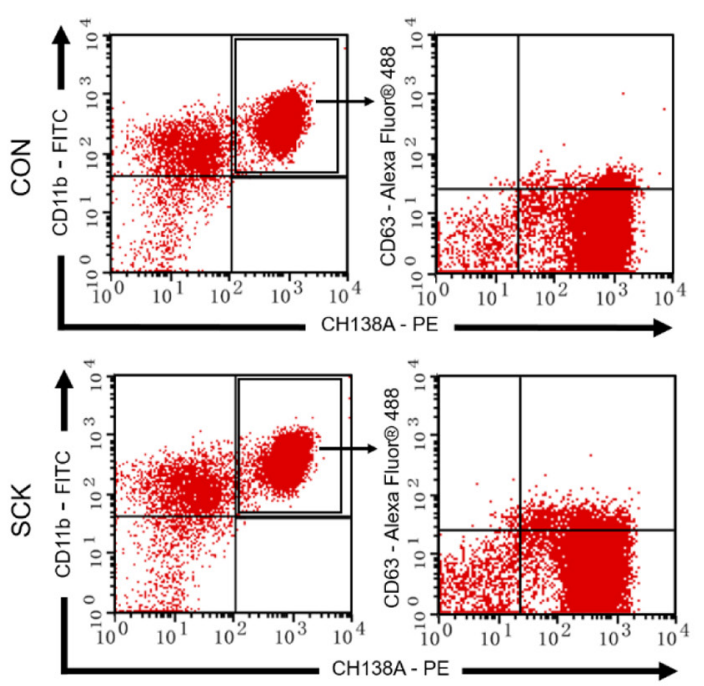

B

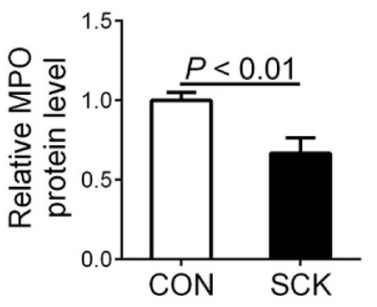

D

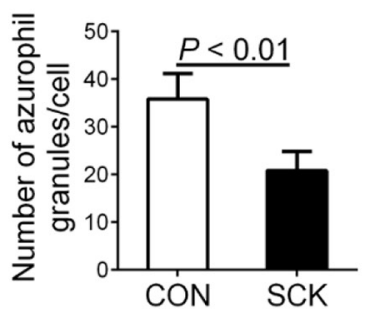

$\mathrm{F}$

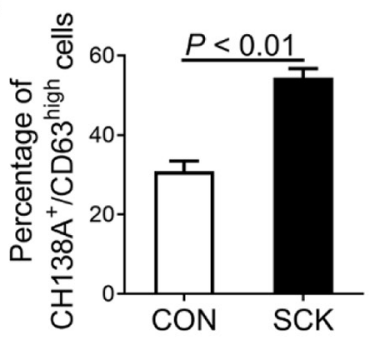

G

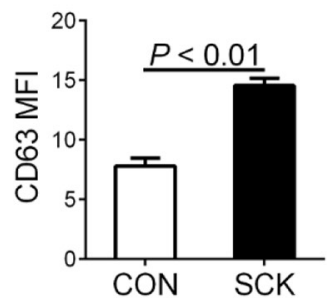

Figure 3. Degranulation of azurophil granules (AG) in PMN of control cows (CON; $\mathrm{n}=15)$ and cows with subclinical ketosis $(\mathrm{SCK} ; \mathrm{n}=15)$. (A) Protein levels of intracellular myeloperoxidase (MPO) in PMN of control and SCK cows. Three wells of each group represent 3 samples from different cows, respectively. (B) Quantification of MPO protein levels in A. (C) Representative transmission electron microscope images showing the AG in PMN of control and SCK cows. AG are indicated by arrowheads. Magnification $=3,000 \times$. Scale bars $=2 \mu \mathrm{m}$. (D) Quantification of the number of AG per cell in C. At least 30 cells of each group were counted for quantification. (E) Flow cytometry analysis of membrane CD63 level in PMN of control and SCK cows. The anti-CD11b and anti-CH138A antibodies were used to label bovine PMN. The anti-CD63 antibody was used to evaluate the degranulation of AG of PMN. (F) Quantification of percentage of CH138A $\mathrm{A}^{+} \mathrm{CD}^{\text {high }}$ cells in PMN in E. (G) Quantification of CD63 mean fluorescence intensity (MFI) in the PMN of control and SCK cows. Data were analyzed with an independentsamples $t$-test. Data are expressed as mean \pm SEM. $P<0.05$ is considered significant and $P<0.01$ as highly significant. 
A

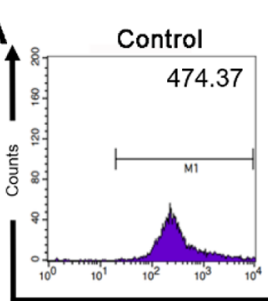

FFA+DPI
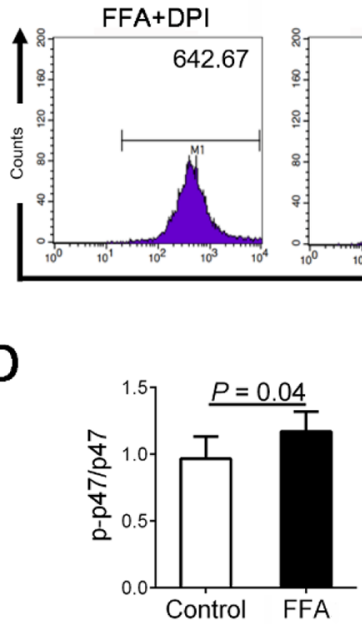

G

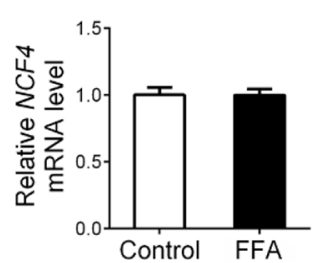

FFA

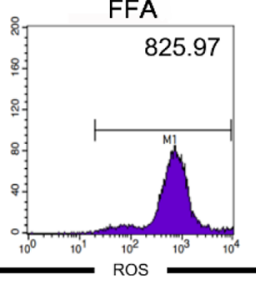

FCCP

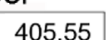

405.55

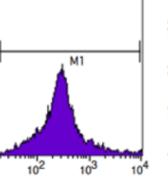

ROS
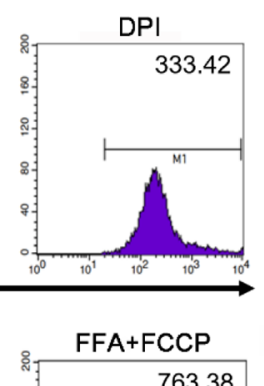

E

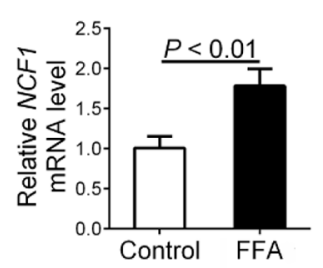

$\mathrm{H}$

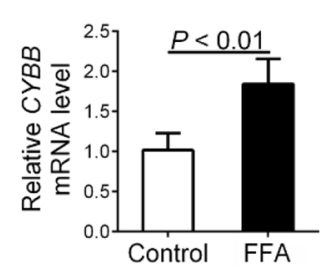

B

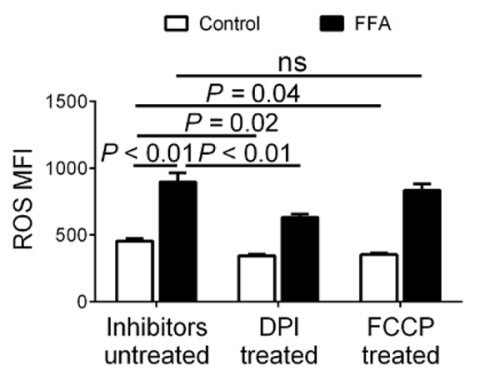

C

p-p47

p47

$\beta$-actin

$\mathrm{F}$

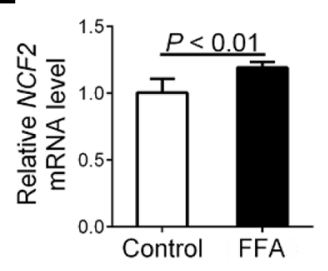

I

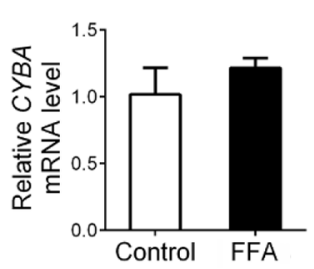

Figure 4. Effects of free fatty acids (FFA) on reactive oxygen species (ROS) production of bovine PMN in vitro. Diphenyleneiodonium chloride (DPI) and carbonyl cyanide 4-(trifluoromethoxy) phenylhydrazone (FCCP) were used to inhibit NADPH oxidase- and mitochondriaderived ROS production, respectively. (A) ROS levels in bovine PMN determined by flow cytometry. DPI, $10 \mu M, 0.5 \mathrm{~h} ; \mathrm{FCCP}, 10 \mu M, 0.5 \mathrm{~h}$. Fluorescence intensity values of the representative graphs of each group are shown in the upper right corner. (B) Quantification of ROS mean fluorescence intensity (MFI) in bovine PMN in A. Two-way ANOVA showed a significant effect of FFA $\times$ DPI interaction $(P<0.01)$ and no significant effect of FFA $\times$ FCCP interaction $(P=0.33)$. (C) Phosphorylation of p47 (p-p47) in PMN with or without FFA treatment. Three wells of each group represent 3 samples from different experiments, respectively. (D) Quantification of p47 phosphorylation in C. (E-I) Relative mRNA abundance of $N C F 1$ (p47), NCF2 (p67), NCF4 (p40), CYBB (gp91), and CYBA (p22) in bovine PMN with or without FFA treatment (FFA, $0.6 \mathrm{~m} M, 1 \mathrm{~h}$ ). Data were analyzed with a 2-way ANOVA with subsequent Bonferroni correction or independent-samples $t$-tests. Data are expressed as mean \pm SEM. $P<0.05$ is considered significant and $P<0.01$ as highly significant; ns $=$ no significant difference.

the increase in $\mathrm{AG}$ degranulation by activating an NADPH oxidase-ROS signaling pathway, which was consistent with the increased blood FFA and enhanced activation of NADPH oxidase-ROS signaling pathway in PMN from SCK cows.

The concentration of serum proinflammatory cytokines, including IL-1, IL-6, IL-8, and TNF- $\alpha$, as well as enhanced positive acute-phase proteins, including HP and SAA, increase in SCK dairy cows (Abuajamieh et al., 2016). These systemic proinflammatory mediators can reduce appetite, cause liver damage, and increase energy consumption by the immune system, thus aggravating the negative energy balance state in dairy cows (Khailova et al., 2020; Swartz et al., 2021). Systemic inflammation can also increase the risk of developing other inflammatory diseases, including mastitis, endometritis, and laminitis in dairy cows (Shen et al., 2019). For example, the incidences of endometritis and laminitis in SCK cows were respectively 2 times and 5 times higher compared with healthy cows (Suthar et al., 2013). In agreement, our data revealed that SCK cows with reduced milk yield had systemic inflammation, emphasizing the possibility for using these acute-phase proteins and proinflammatory cytokines as biomarkers for SCK diagnosis (El-Deeb and El-Bahr, 2017). However, it is worth noting that, in SCK cows that did 
A

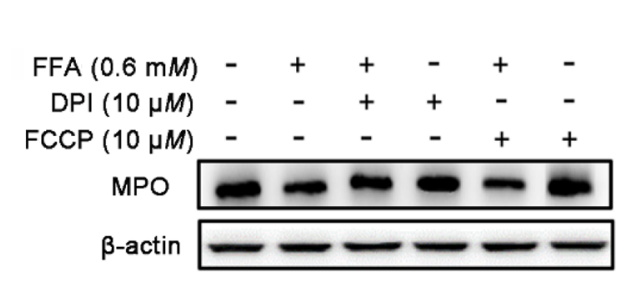

$\mathrm{C}$
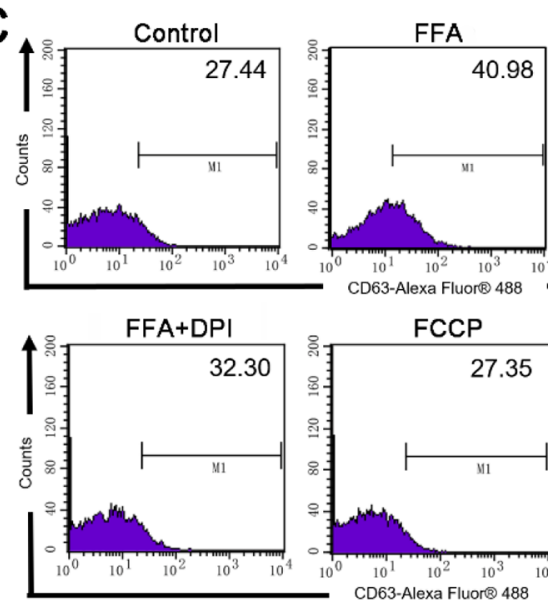
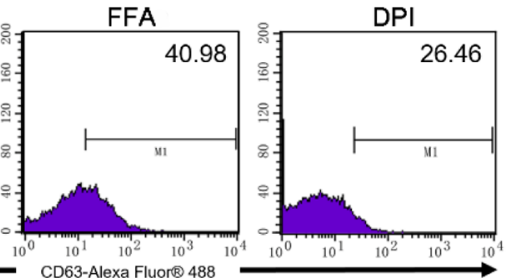

$F F A+F C C P$

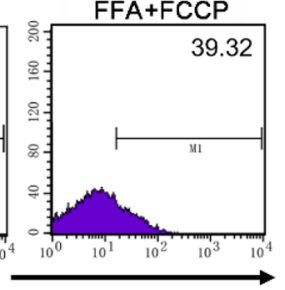

B

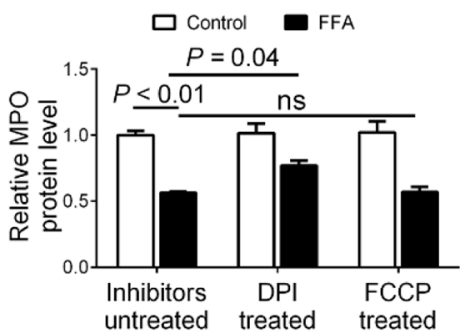

D

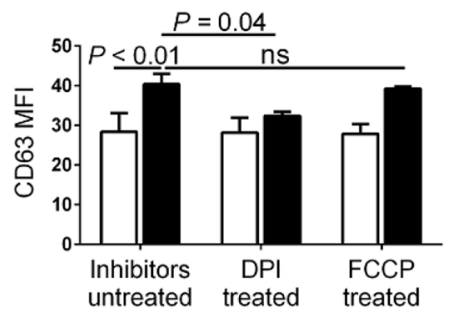

Figure 5. Role of reactive oxygen species (ROS) from different sources in free fatty acid (FFA)-induced azurophil granule (AG) degranulation in bovine PMN in vitro. (A) Protein levels of intracellular myeloperoxidase (MPO) in bovine PMN. (B) Quantification of MPO protein levels in A. Two-way ANOVA showed a significant effect of FFA $\times$ DPI interaction $(P<0.01)$ and no significant effect of FFA $\times$ FCCP interaction $(P$ $=0.66)$. (C) Representative CD63 fluorescence intensity in the bovine PMN. Fluorescence intensity values of the representative graphs of each group are shown in the upper right corner. (D) Quantification of CD63 mean fluorescence intensity (MFI) in PMN. Two-way ANOVA showed a significant effect of FFA $\times$ DPI interaction $(P<0.01)$ and no significant effect of FFA $\times$ FCCP interaction $(P=0.81)$. FFA, $0.6 \mathrm{~m} M, 1 \mathrm{~h}$; DPI, $10 \mu M, 0.5 \mathrm{~h} ; \mathrm{FCCP}, 10 \mu M, 0.5 \mathrm{~h}$. Data were analyzed with a 2-way ANOVA with subsequent Bonferroni correction. Data are expressed as mean \pm SEM. $P<0.05$ is considered significant and $P<0.01$ as highly significant; ns $=$ no significant difference. DPI $=$ diphenyleneiodonium chloride; FCCP = carbonyl cyanide 4-(trifluoromethoxy) phenylhydrazone.

not exhibit a reduction in milk yield, further research would have to be performed to confirm this hypothesis. We further detected greater MPO, the specific marker included in the AG of PMN, in the serum of SCK cows, and concentrations were positively correlated with the content of HP, SAA, IL-1 $\beta$, IL-6, IL-8, and TNF- $\alpha$. In mice, MPO deficiency has been associated with reduced IL-1 $\beta$ content in the skin (Strzepa et al., 2021). In response to $\mathrm{TNF}-\alpha$ stimulation in vitro, dairy cow PMN secrete more MPO into the supernatant (Wessely-Szponder, 2008), suggesting a mutual amplification network between MPO and proinflammatory factors. Taken together, the evidence suggested a potential involvement between overactivated PMN degranulation of AG and systemic inflammation in cows with SCK.

The contents of AG, including MPO, can be released to the extracellular space during degranulation and contribute to inflammation (Faurschou and Borregaard, 2003). Not only is MPO involved in the catalysis of oxidation reactions via the release of reactive halogenating and nitrating species, thereby inducing tissue damage, but it also functions as a proinflammatory factor (Eiserich et al., 1998; Nussbaum et al., 2013). In nonruminants, at a molecular and cellular level, MPO is regarded as a bridge between inflammation and oxidative stress (Ndrepepa, 2019), which partly explains the attenuation of high-fat diet-induced adipose tissue and systemic inflammation in rodents with an MPO knockout (Lin et al., 2017). Extracellular MPO can promote PMN degranulation by activating tyrosine kinase, phosphatidylinositol 3 kinase, and calcium signaling, processes that further amplify PMN degranulation (Grigorieva et al., 2016). In humans and mice, MPO is associated with continuous activation and recruitment of leukocytes to damaged tissue, further enhancing downstream inflammatory cascades (Ali et al., 2016). More importantly, diabetic ketoacidosis in humans is associated with increases in concentrations of leukocyte elastase, proteinase-3, and MPO (Woo et al., 2016). Together, this evidence suggests that enhanced degranulation of AG may be an important cause of systemic inflammation during the onset of metabolic 
A

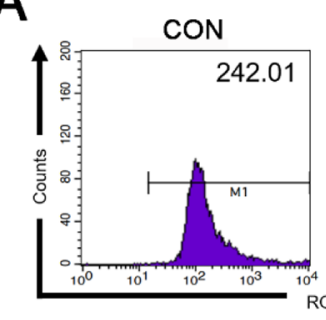

C
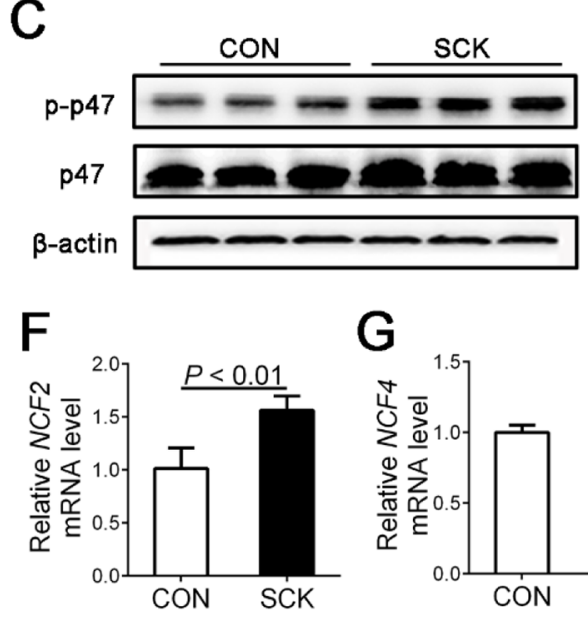

SCK

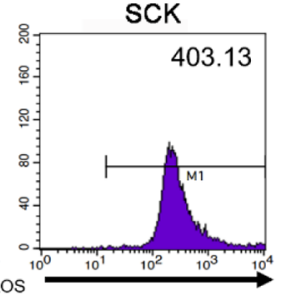

G

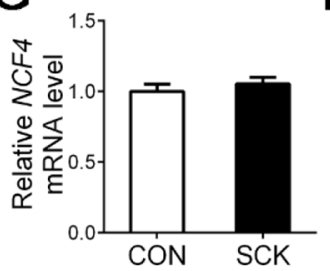

B

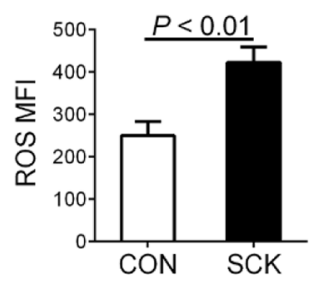

D

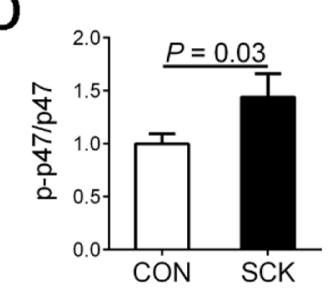

$\mathrm{H}$

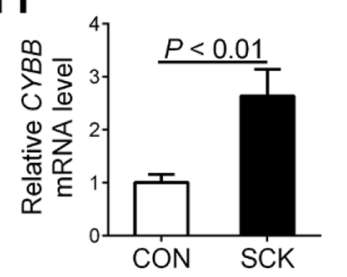

$E$

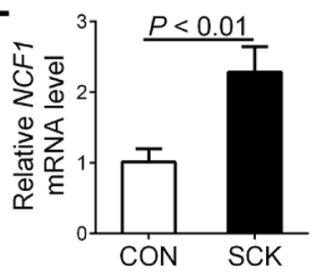

I

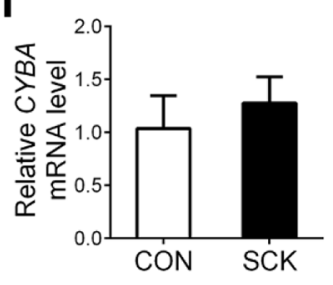

Figure 6. Activation of NADPH oxidase and production of reactive oxygen species (ROS) in PMN of control cows $(\mathrm{CON} ; \mathrm{n}=15)$ and cows with subclinical ketosis (SCK; $\mathrm{n}=15$ ). (A) ROS levels of PMN from control and SCK cows determined by flow cytometry. Fluorescence intensity values of the representative graphs of each group are shown in the upper right corner. (B) Quantification of ROS mean fluorescence intensity (MFI) in PMN in A. (C) Phosphorylation of p47 (p-p47) in PMN of control and SCK cows. Three wells of each group represent 3 samples from different cows, respectively. (D) Quantification of the level of p47 phosphorylation in C. (E-I) Relative mRNA expression levels of NCF1 (p47), NCF2 (p67), NCF4 (p40), CYBB (gp91), and CYBA (p22) in PMN from control and SCK cows. Data were analyzed with an independentsamples $t$-test. Data are expressed as mean \pm SEM. $P<0.05$ is considered significant and $P<0.01$ as highly significant.

diseases such as ketosis. As the present study revealed that SCK cows had enhanced AG degranulation from PMN, we speculated that the development of systemic inflammation in SCK cows occurs in a similar fashion as in nonruminants.

Previous studies with ketotic cows have confirmed that high concentrations of FFA induce lipotoxicity in a variety of tissues and organs, including the liver and adipose tissue, leading to local and systematic inflammation through activation of the NF- $\mathrm{BB}$ and NLRP3 signaling pathways (LeBlanc, 2014; Shi et al., 2015; Shen et al., 2019). At the immune level, FFA can damage the function of both innate and adaptive immune cells (LeBlanc, 2020), likely due to the effect of FFA on proinflammatory cytokine secretion in SCK cows (El-Deeb and El-Bahr, 2017). The fact that intravenous infusion of FFA increased plasma levels of MPO 2-fold (Mathew et al., 2010) in humans suggested a potential relationship between FFA and AG degranulation from PMN. Our data confirmed that FFA treatment in vitro enhanced the AG degranulation in bovine PMN, re- sulting in an increase of MPO in supernatant, thereby providing a potential explanation for the development of systemic inflammation in dairy cows with SCK. In vivo studies are needed to confirm this hypothesis.

The lipotoxic effect of FFA in many tissues and organs is reflected by the damage of mitochondrial integrity, leading to enhanced ROS production (Song et al., 2021). The NADPH oxidase is the main source of ROS production in phagocytes (Lam et al., 2010). Through ex vivo and in vitro experiments, the present data indicated that high levels of FFA activated NADPH oxidase and promoted NADPH oxidase-derived rather than mitochondrial-derived ROS production in PMN of dairy cows with SCK. However, the present study did not perform a viability assay in the flow cytometry experiments, which was a limitation in evaluating the level of ROS and degranulation of bovine PMN. Available evidence suggests that FFA may exert their lipotoxic effect on phagocytes by increasing NADPH oxidase-derived ROS production. It is noteworthy that high levels of FFA stimulate the PKC-dependent activa- 
tion of nonphagocytic cell oxidase (NOX), the homolog of NADPH oxidase in nonphagocytes, a process that leads to increased ROS production in cultured vascular cells (Inoguchi et al., 2000). Whether this mechanism applies to ruminant phagocytes is unknown.

Not only do ROS help kill bacteria, they also act as signal molecules to transmit intracellular information (D'Autréaux and Toledano, 2007). In granulocytes from murine mast cells, the use of antioxidants in vitro and in vivo can inhibit the degranulation process and the production of cytokines (Chelombitko et al., 2016). In the present study, inhibition of NADPH oxidase-derived ROS reduced the AG degranulation of PMN. Thus, such evidence suggested that NADPH oxidase-derived ROS is an important upstream regulator of granulocyte degranulation. From a prevention standpoint, at least in humans, it is important to highlight that enhanced supply of nutrients such as vitamin $\mathrm{E}$ can reduce NADPH oxidase activity in PMN and decrease the level of circulating inflammatory biomarkers (Castilla et al., 2008). Selenium can also inhibit $\mathrm{O}^{2-}$ generation from PMN through the inhibition of NADPH oxidase (Sies, 1993). Both of these nutrients are the most widely used antioxidants, either alone or combined, in the diets of peripartal dairy cows as a way to improve dysfunctional inflammatory responses (Abuelo et al., 2015). Based on our data, these NADPH oxidase-related antioxidants may play a more important role in the regulation of immune system homeostasis in peripartal dairy cows than previously thought.

How ROS regulate PMN degranulation is still an open question. In human aortic endothelial cells, activation of NADPH oxidase increases the sensitivity of the inositol 1,4,5-trisphosphate receptor to inositol 1,4,5-trisphosphate, and thereby plays a role in the generation of $\mathrm{Ca}^{2+}$ (Hu et al., 2002). In the cardiovascular system, increases in ROS oxidize the ryanodine receptor with cysteine residues, resulting in the release of intracellular $\mathrm{Ca}^{2+}$ (Kawakami and Okabe, 1998; Krylatov et al., 2018). In human PMN, the increase of intracellular $\mathrm{Ca}^{2+}$ concentration can induce the release of granules (Hann et al., 2020). Thus, it could be possible that $\mathrm{Ca}^{2+}$ signaling plays an important role in ROS-induced PMN degranulation. However, more data are needed to support this hypothesis.

In conclusion, the present study demonstrated that cows with SCK have enhanced AG degranulation from PMN, and ex vivo and in vitro experiments allowed us to determine that FFA promote AG degranulation through activating an NADPH oxidase-ROS signaling pathway. Considering that AG contain a large number of proinflammatory molecules, including MPO, our findings provide a new viewpoint for the development of systemic inflammation in peripartal cows with SCK. Further in vivo research is needed to establish a causeeffect relationship between blood FFA concentrations and AG degranulation from PMN in dairy cows with SCK.

\section{ACKNOWLEDGMENTS}

This work was supported by the National Natural Science Foundation of China (Beijing; grant nos. 32022084 and 32102737) and the Science Foundation of Education Bureau of Jilin Province (Changchun, China; grant no. JJKH20211135KJ). The authors have not stated any conflicts of interest.

\section{REFERENCES}

Abuajamieh, M., S. K. Kvidera, M. V. Fernandez, A. Nayeri, N. C. Upah, E. A. Nolan, S. M. Lei, J. M. DeFrain, H. B. Green, K. M. Schoenberg, W. E. Trout, and L. H. Baumgard. 2016. Inflammatory biomarkers are associated with ketosis in periparturient Holstein cows. Res. Vet. Sci. 109:81-85. https://doi.org/10.1016/ j.rvsc.2016.09.015.

Abuelo, A., J. Hernández, J. L. Benedito, and C. Castillo. 2015. The importance of the oxidative status of dairy cattle in the periparturient period: Revisiting antioxidant supplementation. J. Anim. Physiol. Anim. Nutr. (Berl.) 99:1003-1016. https://doi.org/10 .1111/.jpn.12273.

Ali, M., B. Pulli, G. Courties, B. Tricot, M. Sebas, Y. Iwamoto, I. Hilgendorf, S. Schob, A. Dong, W. Zheng, A. Skoura, A. Kalgukar, C. Cortes, R. Ruggeri, F. K. Swirski, M. Nahrendorf, L. Buckbinder, and J. W. Chen. 2016. Myeloperoxidase inhibition improves ventricular function and remodeling after experimental myocardial infarction. JACC Basic Transl. Sci. 1:633-643. https://doi.org/10 .1016/j.jacbts.2016.09.004.

Aratani, Y. 2018. Myeloperoxidase: Its role for host defense, inflammation, and neutrophil function. Arch. Biochem. Biophys. 640:47-52. https://doi.org/10.1016/j.abb.2018.01.004.

Borchardt, S., and R. Staufenbiel. 2012. Evaluation of the use of nonesterified fatty acids and $\beta$-hydroxybutyrate concentrations in pooled serum samples for herd-based detection of subclinical ketosis in dairy cows during the first week after parturition. J. Am. Vet. Med. Assoc. 240:1003-1011. https://doi.org/10.2460/javma .240.8.1003.

Brunner, N., S. Groeger, J. Canelas Raposo, R. M. Bruckmaier, and J. J. Gross. 2019. Prevalence of subclinical ketosis and production diseases in dairy cows in Central and South America, Africa, Asia, Australia, New Zealand, and Eastern Europe. Transl. Anim. Sci. 3:84-92. https://doi.org/10.1093/tas/txy102.

Bustin, S. A., V. Benes, J. A. Garson, J. Hellemans, J. Huggett, M. Kubista, R. Mueller, T. Nolan, M. W. Pfaffl, G. L. Shipley, J. Vandesompele, and C. T. Wittwer. 2009. The MIQE guidelines: Minimum information for publication of quantitative real-time PCR experiments. Clin. Chem. 55:611-622. https://doi.org/10 .1373/clinchem.2008.112797.

Castilla, P., A. Dávalos, J. L. Teruel, F. Cerrato, M. Fernández-Lucas, J. L. Merino, C. C. Sánchez-Martín, J. Ortuño, and M. A. Lasunción. 2008. Comparative effects of dietary supplementation with red grape juice and vitamin $\mathrm{E}$ on production of superoxide by circulating neutrophil NADPH oxidase in hemodialysis patients. Am. J. Clin. Nutr. 87:1053-1061. https://doi.org/10.1093/ajcn/ 87.4.1053.

Chelombitko, M. A., A. V. Fedorov, O. P. Ilyinskaya, R. A. Zinovkin, and B. V. Chernyak. 2016. Role of reactive oxygen species in mast 
cell degranulation. Biochemistry (Mosc.) 81:1564-1577. https:// doi.org/10.1134/S000629791612018X.

Contreras, G. A., W. Raphael, S. A. Mattmiller, J. Gandy, and L. M. Sordillo. 2012. Nonesterified fatty acids modify inflammatory response and eicosanoid biosynthesis in bovine endothelial cells. J. Dairy Sci. 95:5011-5023. https://doi.org/10.3168/jds.2012-5382.

D'Autréaux, B., and M. B. Toledano. 2007. ROS as signalling molecules: Mechanisms that generate specificity in ROS homeostasis. Nat. Rev. Mol. Cell Biol. 8:813-824. https://doi.org/10.1038/ nrm2256.

Daha, M. R. 2011. Grand challenges in molecular innate immunity. Front. Immunol. 2:16. https://doi.org/10.3389/fimmu.2011.00016.

De Ketelaere, A., K. Goossens, L. Peelman, and C. Burvenich. 2006. Technical note: Validation of internal control genes for gene expression analysis in bovine polymorphonuclear leukocytes. J. Dairy Sci. 89:4066-4069. https://doi.org/10.3168/jds.S0022 -0302(06)72450-X.

Depreester, E., E. Meyer, K. Demeyere, M. Van Eetvelde, M. Hostens, and G. Opsomer. 2017. Flow cytometric assessment of myeloperoxidase in bovine blood neutrophils and monocytes. J. Dairy Sci. 100:7638-7647. https://doi.org/10.3168/jds.2016-12186.

Duffield, T. F., K. D. Lissemore, B. W. McBride, and K. E. Leslie. 2009. Impact of hyperketonemia in early lactation dairy cows on health and production. J. Dairy Sci. 92:571-580. https://doi.org/ 10.3168/jds.2008-1507.

Eiserich, J. P., M. Hristova, C. E. Cross, A. D. Jones, B. A. Freeman, B. Halliwell, and A. van der Vliet. 1998. Formation of nitric oxidederived inflammatory oxidants by myeloperoxidase in neutrophils. Nature 391:393-397. https://doi.org/10.1038/34923.

El-Benna, J., M. Hurtado-Nedelec, V. Marzaioli, J. C. Marie, M. A. Gougerot-Pocidalo, and P. M. Dang. 2016. Priming of the neutrophil respiratory burst: Role in host defense and inflammation. Immunol. Rev. 273:180-193. https://doi.org/10.1111/imr.12447.

El-Deeb, W. M., and S. M. El-Bahr. 2017. Biomarkers of ketosis in dairy cows at postparturient period: Acute phase proteins and proinflammatory cytokines. Vet. Arh. 87:431-440. https://doi.org/10 .24099/vet.arhiv.160126c.

FASS Inc. 2010. Guidelines for the Care and Use of Agricultural Animals in Research and Teaching. 3rd ed. Federation of Animal Science Societies (FASS) Inc.

Faurschou, M., and N. Borregaard. 2003. Neutrophil granules and secretory vesicles in inflammation. Microbes Infect. 5:1317-1327. https://doi.org/10.1016/j.micinf.2003.09.008.

Grigorieva, D. V., I. V. Gorudko, A. V. Sokolov, V. A. Kostevich, V. B. Vasilyev, S. N. Cherenkevich, and O. M. Panasenko. 2016. Myeloperoxidase stimulates neutrophil degranulation. Bull. Exp. Biol. Med. 161:495-500. https://doi.org/10.1007/s10517-016-3446-7.

Guerra, B. A., and R. Otton. 2011. Impact of the carotenoid astaxanthin on phagocytic capacity and ROS/RNS production of human neutrophils treated with free fatty acids and high glucose. Int. Immunopharmacol. 11:2220-2226. https://doi.org/10.1016/j.intimp .2011.10.004

Hann, J., J. L. Bueb, F. Tolle, and S. Bréchard. 2020. Calcium signaling and regulation of neutrophil functions: Still a long way to go. J. Leukoc. Biol. 107:285-297. https://doi.org/10.1002/JLB.3RU0719 $-241 \mathrm{R}$.

Hu, Q., Z. X. Yu, V. J. Ferrans, K. Takeda, K. Irani, and R. C. Ziegelstein. 2002. Critical role of NADPH oxidase-derived reactive oxygen species in generating $\mathrm{Ca}^{2+}$ oscillations in human aortic endothelial cells stimulated by histamine. J. Biol. Chem. 277:3254632551. https://doi.org/10.1074/jbc.M201550200.

Inoguchi, T., P. Li, F. Umeda, H. Y. Yu, M. Kakimoto, M. Imamura, T. Aoki, T. Etoh, T. Hashimoto, M. Naruse, H. Sano, H. Utsumi, and H. Nawata. 2000. High glucose level and free fatty acid stimulate reactive oxygen species production through protein kinase Cdependent activation of $\mathrm{NAD}(\mathrm{P}) \mathrm{H}$ oxidase in cultured vascular cells. Diabetes 49:1939-1945. https://doi.org/10.2337/diabetes.49 .11.1939.

Kawakami, M., and E. Okabe. 1998. Superoxide anion radical-triggered $\mathrm{Ca}^{2+}$ release from cardiac sarcoplasmic reticulum through ryanodine receptor $\mathrm{Ca}^{2+}$ channel. Mol. Pharmacol. 53:497-503. https://doi.org/10.1124/mol.53.3.497.

Khailova, L. S., T. V. Vygodina, G. Y. Lomakina, E. A. Kotova, and Y. N. Antonenko. 2020. Bicarbonate suppresses mitochondrial membrane depolarization induced by conventional uncouplers. Biochem. Biophys. Res. Commun. 530:29-34. https://doi.org/10 .1016/j.bbrc.2020.06.131.

Krylatov, A. V., L. N. Maslov, N. S. Voronkov, A. A. Boshchenko, S. V. Popov, L. Gomez, H. Wang, A. S. Jaggi, and J. M. Downey. 2018. Reactive oxygen species as intracellular signaling molecules in the cardiovascular system. Curr. Cardiol. Rev. 14:290-300. https://doi .org/10.2174/1573403X14666180702152436.

Lam, G. Y., J. Huang, and J. H. Brumell. 2010. The many roles of NOX2 NADPH oxidase-derived ROS in immunity. Semin. Immunopathol. 32:415-430. https://doi.org/10.1007/s00281-010-0221-0.

LeBlanc, S. J. 2014. Reproductive tract inflammatory disease in postpartum dairy cows. Animal 8(Suppl. 1):54-63. https://doi.org/10 $.1017 /$ S1751731114000524.

LeBlanc, S. J. 2020. Review: Relationships between metabolism and neutrophil function in dairy cows in the peripartum period. Animal 14(Suppl. 1):s44-s54. https://doi.org/10.1017/ S1751731119003227.

Lin, H., B. S. Levison, J. A. Buffa, Y. Huang, X. Fu, Z. Wang, V. Gogonea, J. A. DiDonato, and S. L. Hazen. 2017. Myeloperoxidasemediated protein lysine oxidation generates 2-aminoadipic acid and lysine nitrile in vivo. Free Radic. Biol. Med. 104:20-31. https: //doi.org/10.1016/j.freeradbiomed.2017.01.006.

Liu, L., X. Li, Y. Li, Y. Guan, Y. Song, L. Yin, H. Chen, L. Lei, J. Liu, X. Li, Z. Wang, X. Yang, and G. Liu. 2014. Effects of nonesterified fatty acids on the synthesis and assembly of very low density lipoprotein in bovine hepatocytes in vitro. J. Dairy Sci. 97:1328-1335. https://doi.org/10.3168/jds.2013-6654.

Martens, H. 2020. Transition period of the dairy cow revisited: II Homeorhetic stimulus and ketosis with implication for fertility. J. Agric. Sci. (Toronto) 12:25. https://doi.org/10.5539/jas.v12n3p25.

Mathew, M., E. Tay, and K. Cusi. 2010. Elevated plasma free fatty acids increase cardiovascular risk by inducing plasma biomarkers of endothelial activation, myeloperoxidase and PAI-1 in healthy subjects. Cardiovasc. Diabetol. 9:9. https://doi.org/10.1186/1475 -2840-9-9.

Moyes, K. M., D. E. Graugnard, M. J. Khan, M. Mukesh, and J. J. Loor. 2014. Postpartal immunometabolic gene network expression and function in blood neutrophils are altered in response to prepartal energy intake and postpartal intramammary inflammatory challenge. J. Dairy Sci. 97:2165-2177. https://doi.org/10.3168/jds .2013-7433.

Ndrepepa, G. 2019. Myeloperoxidase - A bridge linking inflammation and oxidative stress with cardiovascular disease. Clin. Chim. Acta 493:36-51. https://doi.org/10.1016/j.cca.2019.02.022.

Nussbaum, C., A. Klinke, M. Adam, S. Baldus, and M. Sperandio. 2013. Myeloperoxidase: A leukocyte-derived protagonist of inflammation and cardiovascular disease. Antioxid. Redox Signal. 18:692-713. https://doi.org/10.1089/ars.2012.4783.

Shen, T., X. Li, J. J. Loor, Y. Zhu, X. Du, X. Wang, D. Xing, Z. Shi, Z. Fang, X. Li, and G. Liu. 2019. Hepatic nuclear factor kappa B signaling pathway and NLR family pyrin domain containing 3 inflammasome is over-activated in ketotic dairy cows. J. Dairy Sci. 102:10554-10563. https://doi.org/10.3168/jds.2019-16706.

Shi, X., D. Li, Q. Deng, Y. Li, G. Sun, X. Yuan, Y. Song, Z. Wang, X. Li, X. Li, and G. Liu. 2015. NEFAs activate the oxidative stressmediated NF- $\kappa \mathrm{B}$ signaling pathway to induce inflammatory response in calf hepatocytes. J. Steroid Biochem. Mol. Biol. 145:103112. https://doi.org/10.1016/j.jsbmb.2014.10.014.

Sies, H. 1993. Ebselen, a selenoorganic compound as glutathione peroxidase mimic. Free Radic. Biol. Med. 14:313-323. https://doi .org/10.1016/0891-5849(93)90028-S.

Song, Y., N. Li, J. Gu, S. Fu, Z. Peng, C. Zhao, Y. Zhang, X. Li, Z. Wang, X. Li, and G. Liu. 2016. $\beta$-Hydroxybutyrate induces bovine hepatocyte apoptosis via an ROS-p38 signaling pathway. J. Dairy Sci. 99:9184-9198. https://doi.org/10.3168/jds.2016-11219. 
Song, Y., J. J. Loor, C. Li, Y. Liang, N. Li, X. Shu, Y. Yang, X. Feng, X. Du, Z. Wang, G. Liu, and X. Li. 2021. Enhanced mitochondrial dysfunction and oxidative stress in the mammary gland of cows with clinical ketosis. J. Dairy Sci. 104:6909-6918. https://doi.org/ $10.3168 /$ jds. $2020-19964$.

Strzepa, A., C. J. Gurski, L. J. Dittel, M. Szczepanik, K. A. Pritchard Jr., and B. N. Dittel. 2021. Neutrophil-derived myeloperoxidase facilitates both the induction and elicitation phases of contact hypersensitivity. Front. Immunol. 11:608871. https://doi.org/10 .3389/fimmu.2020.608871.

Suthar, V. S., J. Canelas-Raposo, A. Deniz, and W. Heuwieser. 2013. Prevalence of subclinical ketosis and relationships with postpartum diseases in European dairy cows. J. Dairy Sci. 96:2925-2938. https://doi.org/10.3168/jds.2012-6035.

Swartz, T. H., U. Moallem, H. Kamer, G. Kra, Y. Levin, L. K. Mamedova, B. J. Bradford, and M. Zachut. 2021. Characterization of the liver proteome in dairy cows experiencing negative energy balance at early lactation. J. Proteomics 246:104308. https://doi.org/ 10.1016/j.jprot.2021.104308

Vallejo-Timarán, D. J. Reyes-Vélez, J. VanLeeuwen, J. MaldonadoEstrada, and J. Astaiza-Martínez. 2020. Incidence and effects of subacute ruminal acidosis and subclinical ketosis with respect to postpartum anestrus in grazing dairy cows. Heliyon 6:e03712. https://doi.org/10.1016/j.heliyon.2020.e03712.

Wessely-Szponder, J. 2008. The influence of TNFo and IL-8 on secretory action of neutrophils isolated from heifers in the course of bovine respiratory disease. Acta Vet. Hung. 56:187-196. https:// doi.org/10.1556/avet.56.2008.2.6

Woo, M. M., E. K. Patterson, C. Clarson, G. Cepinskas, M. BaniYaghoub, D. B. Stanimirovic, and D. D. Fraser. 2016. Elevated leukocyte azurophilic enzymes in human diabetic ketoacidosis plasma degrade cerebrovascular endothelial junctional proteins. Crit. Care Med. 44:e846-e853. https://doi.org/10.1097/CCM .0000000000001720

Zhang, X., L. Ding, and A. J. Sandford. 2005. Selection of reference genes for gene expression studies in human neutrophils by real-time PCR. BMC Mol. Biol. 6:4. https://doi.org/10.1186/1471-2199-6-4.

Zhang, Y., X. Li, H. Zhang, Z. Zhao, Z. Peng, Z. Wang, G. Liu, and X. Li. 2018. Non-esterified fatty acids over-activate the TLR2/4$\mathrm{NF}-\mathrm{Kb}$ signaling pathway to increase inflammatory cytokine synthesis in neutrophils from ketotic cows. Cell. Physiol. Biochem. 48:827-837. https://doi.org/10.1159/000491913. 